\title{
Do Mesenchymal Stromal Cells Influence Microscopic Residual or Metastatic Osteosarcoma in a Murine Model?
}

\author{
Megan E. Aanstoos MS, Daniel P. Regan DVM, Ruth J. Rose DVM, \\ Laura S. Chubb BS, Nicole P. Ehrhart VMD
}

Published online: 28 May 2015

(C) The Association of Bone and Joint Surgeons (B) 2015

\begin{abstract}
Background Mesenchymal stromal cells (MSCs) have been shown in rodent models to promote primary and pulmonary metastatic sarcoma growth when injected in the presence of gross tumor. In theory, this would limit their use in a clinical setting after limb salvage treatment for osteosarcoma. Although concerning, these models do not
\end{abstract}

Each author certifies that he or she, or a member of his or her immediate family, has no funding or commercial associations (eg, consultancies, stock ownership, equity interest, patent/licensing arrangements, etc) that might pose a conflict of interest in connection with the submitted article.

All ICMJE Conflict of Interest Forms for authors and Clinical Orthopaedics and Related Research ${ }^{\mathbb{R}}$ editors and board members are on file with the publication and can be viewed on request. Clinical Orthopaedics and Related Research ${ }^{\circledR}$ neither advocates nor endorses the use of any treatment, drug, or device. Readers are encouraged to always seek additional information, including FDA-approval status, of any drug or device prior to clinical use. Each author certifies that his or her institution approved the animal protocol for this investigation and that all investigations were conducted in conformity with ethical principles of research.

M. E. Aanstoos

School of Biomedical Engineering, Colorado State University, Fort Collins, CO, USA

D. P. Regan

Department of Microbiology, Immunology, \& Pathology,

Colorado State University, Fort Collins, CO, USA

R. J. Rose, L. S. Chubb

Department of Clinical Sciences, Colorado State University, Fort Collins, CO, USA

\section{N. P. Ehrhart $(\bowtie)$}

Department of Clinical Sciences and School of Biomedical Engineering, Colorado State University, 300 W Drake Road, Fort Collins, CO 80525, USA

e-mail: Nicole.ehrhart@colostate.edu translate to the clinical setting wherein MSCs could be used after primary tumor resection to aid in bone healing and incorporation of tumor endoprostheses. If we can determine whether the use of MSCs in this setting is safe, it might improve our ability to augment bone healing in patients undergoing limb salvage.

Questions/purposes The purpose of this study was to determine (1) whether MSCs promote pulmonary metastatic disease progression in a murine osteosarcoma model; and/or (2) whether they affect local disease recurrence in the presence of microscopic residual osteosarcoma.

Methods An orthotopic model of luciferase-expressing osteosarcoma was developed. At 10 days, resection of the primary tumor was performed. One hundred fourteen female $\mathrm{C} 3 \mathrm{H}$ mice were inoculated with DLM8-luc osteosarcoma in the proximal tibia. Ninety-four mice developed orthotopic osteosarcoma with luciferase expression. Mice with bioluminescent evidence of a primary tumor received either a microscopically "clean" amputation at a time when residual microscopic metastatic disease was present in the lungs (pulmonary metastasis group; $\mathrm{n}=65$ ) or a "dirty" amputation (local recurrence group; $n=29$ ). Mice were randomized to receive intravenous MSCs, MSCs at the surgical site, or no MSCs. Mice were monitored for development and progression of pulmonary metastasis and local recurrence by bioluminescence imaging and daily measurements at the surgical site. The number of pulmonary nodules, time to first evidence of metastasis, and size of recurrent tumor were compared using Kruskal-Wallis, analysis of variance, Welch's, t-tests, or Mann-Whitney tests as appropriate for the specific data sets with $\mathrm{p}<0.05$ considered significant. Results Mice receiving intravenous MSCs had a faster time to first detection of pulmonary metastasis $(2.93 \pm 1.90$ days) compared with mice with local injection of MSCs $(6.94 \pm 6.78$ days $)$ or no MSCs $(5.93 \pm 4.55$ days $)$ 
$(p=0.022)$. MSC treatment did not influence whether mice developed local recurrence $(p=0.749)$ or size of recurrent tumors $(\mathrm{p}=0.221)$.

Conclusions MSCs delivered to the surgical site did not promote local recurrence or size of recurrent tumors, but intravenous injection of MSCs did hasten onset of detection of pulmonary metastatic disease. Although local administration of MSCs into a surgical site does not appear to promote either pulmonary metastatic disease or local recurrence, large variation within groups and small numbers diminished statistical power such that a Type II error cannot be ruled out.

Clinical Relevance If MSCs are to be used to augment bone healing in the postlimb salvage setting in patients with osteosarcoma, it will be important to understand their influence, if any, on pulmonary micrometastsis or residual microscopic local disease. Although murine models do not completely recapitulate the clinical scenario, these results suggest that intravenous delivery of MSCs may promote micrometastatic pulmonary disease. Local administration into a surgical wound, even in the presence of residual microscopic disease, may be safe, at least in this murine model, but further investigation is warranted before considering the use of MSCs for clinical use in patients with osteosarcoma.

\section{Introduction}

Osteosarcoma is the second most common cause of cancerrelated deaths in children and adolescents. It arises most frequently in the appendicular skeleton [25] and pulmonary micrometastases are presumed to be present at initial diagnosis [21]. Wide resection of the primary tumor with limb salvage is currently the standard surgical approach when possible; however, large-segment bone reconstruction presents many challenges for the surgeon because it is associated with a high complication rate and frequent need for revision procedures arising from allograft failure, infection, local recurrence, and other factors [8, 22, 23, 26]. Mesenchymal stromal cells (MSCs) have been shown to improve bone integration between native tissue and largesegment cortical allografts or allo- endoprosthetic composites used in limb reconstruction $[5,7,13]$. As well, they have been shown to aid in healing of critical-sized defects in several preclinical studies. MSCs therefore have potential for therapeutic use in limb salvage after large-segment bone loss resulting from trauma or tumor resection $[10,12$, 17]. However, MSCs have also been shown to promote primary tumor and pulmonary metastatic tumor growth when injected either locally near existing gross tumor or coinjected with sarcoma cells in rodent models [3, 14]. Although these results raise concerns about the safety of using MSCs in patients with sarcoma, MSCs are unlikely to be used in a clinical setting when gross tumor is present. Instead, they are potentially useful in combination with other treatments for improvement of bone healing and integration of an endoprosthesis and/or allograft after tumor resection. What remains unclear, however, is whether MSCs are safe to use in this setting. Previous studies suggest that MSCs might influence osteosarcoma progression in a minimal residual disease setting when tumor cells are coinjected with MSCs [28]. To our knowledge, no previous studies have explored the influence of MSCs on progression of osteosarcoma in a microscopic disease setting after surgical removal of the primary tumor. We endeavored to develop a murine osteosarcoma model to test whether MSCs promote metastatic or local tumor growth after osteosarcoma resection.

Several rodent models of osteosarcoma have been developed to study pulmonary metastasis $[2,6,16,18,19$, 27]. These models vary widely from scenarios where the primary tumor remains in situ throughout the study to others where the primary tumor is resected before analyzing metastatic growth to models where cell lines are injected into the right ventricle to seed lungs directly. The difference between models makes it difficult to compare results $[6,16,18,19,27]$. Orthotopic tumor models with spontaneous metastasis are thought to most accurately recapitulate tumor-stroma interactions in the tumor microenvironment $[6,27]$. MSCs are known to exist in both the stromal tissues and the circulating blood [15].

Therefore, the purposes of this study were (1) to use an orthotopic, spontaneously metastasizing murine model of minimal residual osteosarcoma to determine whether the administration of adipose-derived MSCs (AD-MSCs) would promote pulmonary metastatic osteosarcoma progression after primary tumor removal; and (2) to develop a model of local recurrence of osteosarcoma to mimic microscopic residual disease left behind after a histologically incomplete excision of the primary tumor and assess the effects of AD-MSC administration on local tumor recurrence. We hypothesized that AD-MSCs, injected either locally at the surgical site or intravenously after amputation for tibial osteosarcoma, would not influence pulmonary metastatic disease progression after primary tumor resection. Additionally, we hypothesized that ADMSCs, injected either at the surgical site or intravenously after incomplete excision of osteosarcoma (residual microscopic local tumor), would not influence local recurrence of osteosarcoma once the primary tumor had been removed. 


\section{Materials and Methods}

\section{Osteosarcoma Cell Line}

The parental DLM8 cell line, a syngeneic murine osteosarcoma cell line [1,9], was maintained in Dulbecco's Modification of Eagle's Medium (DMEM; Corning, Manassas, VA, USA) supplemented with $15 \%$ fetal bovine serum (FBS; Atlas Biologicals, Fort Collins, CO, USA) and antibiotic-antimycotic in a $5 \% \mathrm{CO}_{2}$ and $95 \%$ air atmosphere at $37^{\circ} \mathrm{C}$. Once confluent, cells were washed with Hank's balanced salt solution (HBSS; Corning) and detached with $0.25 \%$ trypsin. The parental cell line was transfected to express luciferase using a commercial kit containing the pGL3 Luciferase Reporter Vector (Promega, Madison, WI, USA) and pCI-neo Mammalian Expression Vector (Promega) in combination with the SuperFect Transfection Reagent (Qiagen, Valencia, CA, USA).

To select for cells with pulmonary metastatic potential, $1 \times 10^{5}$ DLM8-luc cells were trypinized, washed in HBSS, resuspended in sterile phosphate-buffered saline (PBS; Fisher, Pittsburgh, PA, USA), and injected orthotopically into the proximal tibia of $\mathrm{C} 3 \mathrm{H}$ mice. After 21 days, cells were harvested from pulmonary tissues containing metastatic nodules using the Fidler methodology [11]. Bioluminescent imaging (In Vivo Imaging System [IVIS], Perkin Elmer, Waltham, MA, USA) was used to confirm cells carried the luciferase gene. Cells were maintained in culture medium and passaged on reaching $90 \%$ confluence.

\section{Animals}

All animal studies were performed with approval of the Institutional Animal Care and Use Committee. Female 8- to 10-week-old $\mathrm{C} 3 \mathrm{H}$ mice were obtained from the National Institutes of Health (Bethesda, MD, USA) and housed under standard conditions. Surgical and injection sites were prepared by shaving the fur followed by cleaning the site with chlorhexidine and $70 \%$ alcohol. A subcutaneous injection of sustained-release buprenorphine (ZooPharm, Fort Collins, CO, USA) was given immediately before the procedure. Anesthesia was induced and maintained using a $3 \%$ isoflurane-oxygen mixture. Postoperative care included subcutaneous saline for hydration and recovery in a clean cage on a warming pad until ambulatory. Mice were monitored after procedures daily for 3 days and then at least three times weekly for evidence of morbidity related to the primary tumor, local recurrence, or metastases.
Establishment of Primary Tumor

DLM8-luc-M1 tumor cells were washed twice before being resuspended in sterile PBS to a final concentration of $2 \times 10^{7}$ cells $/ \mathrm{mL}$. A volume of $50 \mu \mathrm{L}\left(1 \times 10^{6}\right.$ cells $)$ was drawn into a 1 -cc Luer-lock syringe and a sterile $22-\mathrm{G}$ needle was attached. Mice $(\mathrm{n}=114)$ were prepared as described previously and the needle was inserted through the cortex of the tibial crest oriented proximal to distal and the cells injected.

Ten days after tumor inoculation, 65 mice were assigned to the pulmonary metastasis study group and the tumorbearing limb was amputated by coxofemoral disarticulation. Twenty-nine mice were assigned to the local tumor recurrence study group and had the tumor removed by partial limb resection immediately proximal to the tumor. Tumor-bearing limbs were collected and examined to ensure histological evidence of the primary tumor. Only mice with histological evidence of primary tumor formation were included in the pulmonary metastasis study or local recurrence study.

\section{Surgical Methods}

For mice assigned to the local recurrence study, amputation was performed using a narrow-margin excision at the femorotibial joint immediately adjacent to the gross primary tumor capsule. This method consistently results in microscopically incomplete margins at the excised tissue plane. Microscopically incomplete margins were confirmed by histology. For mice assigned to the pulmonary metastasis study, amputation was performed at the coxofemoral joint to achieve a wide-margin excision.

\section{Mesenchymal Stromal Cell Isolation}

Mesenchymal stromal cells used for the experiment were harvested from the abdominal adipose of $15 \mathrm{C} 3 \mathrm{H}$ mice under sterile conditions. In brief, the tissue was collected using sterile instrumentation, washed in HBSS, and minced mechanically using \#10 blades. It was then moved into a 25-mL Erlenmeyer flask with a stir bar and enzymatically digested in $1 \mathrm{mg} / \mathrm{mL}$ Type I collagenase for 30 minutes at $37{ }^{\circ} \mathrm{C}$ on a stir plate. The digested tissue was transferred to a $50-\mathrm{mL}$ conical tube and combined with DMEM (low glucose; Corning) and centrifuged at $2000 \mathrm{rpm}$ for 5 minutes, gently agitated, and spun for 5 minutes at 2000 rpm. The supernatant was discarded and the pellet was plated. Cells were expanded in culture medium consisting 
of DMEM, low glucose supplemented with $15 \%$ FBS, antibiotic-antimycotic, MEM vitamins (Corning), and MEM nonessential amino acids (Corning). When cells reached $75 \%$ to $80 \%$ confluence, they were washed with HBSS and detached with $0.25 \%$ trypsin. Cells from Passages 2 through 4 were used for all experiments.

\section{Mesenchymal Stromal Cell Treatment}

To evaluate the influence of AD-MSC on residual microscopic disease, we separated the mice into three MSC treatment groups (Fig. 1). Twenty-four hours after the removal of the primary tumor, mice were randomly assigned to an injection of AD-MSCs into the surgical site (pulmonary metastasis study group, $\mathrm{n}=23$; local recurrence study group, $\mathrm{n}=10$ ), an injection of AD-MSCs intravenously through the tail vein (pulmonary metastasis study group, $n=20$; local recurrence study group, $n=10$ ), or a control group with no AD-MSCs or other injection (pulmonary metastasis study group, $\mathrm{n}=22$; local recurrence study group, $n=9$ ). Mice in the AD-MSC treatment groups received one injection of $5 \times 10^{5}$ AD-MSCs in sterile PBS $+10 \%$ Heparin (Fresenius Kabi USA, LLC, Schaumburg, IL, USA) through a $29 \frac{1}{2}-\mathrm{G}$ insulin needle (Becton Dickinson, East Rutherford, NJ, USA) and were allowed to recover at room temperature in a clean cage.

\section{Bioluminescent Imaging}

Development of the primary tumor was tracked using bioluminescent imaging on the IVIS 100 system (IVIS; Perkin Elmer). Twenty-four hours after tumor inoculation, mice were injected intraperitoneally with $100 \mu \mathrm{L}$ of luciferin $(30 \mathrm{mg} / \mathrm{mL}$ in PBS; D-luciferin; Gold Biotechnology, St Louis, MO, USA) and anesthetized with a $3 \%$ isoflurane-oxygen mixture and imaged while under anesthesia for 3 minutes in right lateral recumbency. Images were analyzed using Living Image Software (Living Image 4.2; Perkin Elmer) for luciferase activity and image analysis was repeated at Days 4, 7, and 10. After removal of the primary tumor, images were obtained at Days 11, 14, $17,21,24,31$, and 39 postinoculation to track development and progression of pulmonary metastatic disease or local recurrence. Mice were euthanized after a final image at 31 days (pulmonary metastasis study group, $\mathrm{n}=65$ ) or at 39 days (local recurrence study group, $\mathrm{n}=29$ ). The mean time to first detection of metastasis as determined by bioluminescence imaging in each MSC treatment group was compared.

Histopathologic Analysis

At the time of amputation, primary tumor-bearing limbs were formalin-fixed, decalcified, and paraffin-embedded. Two longitudinal sections $20 \mu \mathrm{m}$ apart of the proximal tibia and femur were stained with hematoxylin and eosin (H\&E) and examined histologically to confirm the presence of a primary tumor. After assignment of treatment group and completion of the in-life portion of the study, animals were euthanized and tissues at the amputation site, including surrounding bone, muscle, and skin, were grossly examined for tumor recurrence and measured. Tissue was formalin-fixed, decalcified, stained with H\&E, and examined in longitudinal sections, $20 \mu \mathrm{m}$ apart, for the presence of local tumor recurrence.

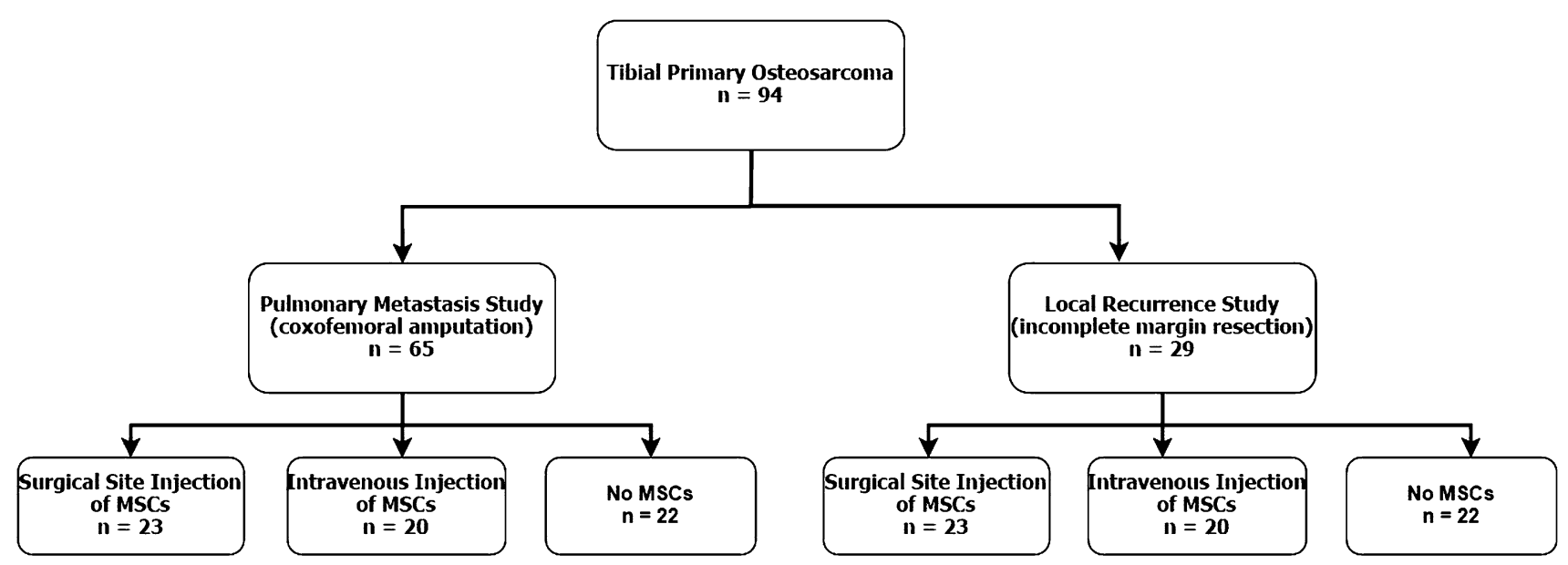

Fig. 1 Chart describing treatment groups. Ninety-four mice with primary tibial osteosarcoma were assigned to either the pulmonary metastasis study or the local recurrence study. Within each of these

studies, the mice were assigned to one of three MSC treatment groups: (1) surgical site injection of MSCs; (2) intravenous injection of MSCs; or (3) no MSCs. 
Lung lobes within each individual study animal were separated and examined individually. Lung lobes were formalin-fixed, paraffin-embedded, sectioned, and stained with H\&E. Two coronal plane lung sections $20 \mu \mathrm{m}$ apart, from the ventral to dorsal surface of each lung lobe, were analyzed for the presence of disease and the number of metastatic tumor nodules. The number of nodules within each animal's lung sections was counted and the mean numbers of nodules within each MSC treatment group were calculated; means between MSC treatment groups were compared. Mean metastatic area measurements were obtained to assess tumor burden area relative to total lung area using Bioquant (Bioquant Osteo 2012 Version 12.1.6; Bioquant Image Analysis Corp, Nashville, TN, USA) software.

\section{Gross Tumor Analysis}

Tumor measurements in mediolateral, AP, and cranialcaudal dimensions were obtained using calipers (Absolute Digimatic; Mitutoyo Corp, Kawaski, Japan) before placement in formalin for tissue processing. Volume was estimated using a formula from Comstock et al [6].

Tumor Volume $=\frac{(\text { long dimension }) *(\text { short dimension })^{2}}{2}$

The AP dimension and the tumor volume were averaged, expressed as means, and compared between treatment groups.

Primary tumor growth after 10 days was documented in $82 \%$ of mice inoculated with the DLM8-luc-M1 tumor cells (Figs. 1,2) and confirmation of primary osteosarcoma tumor growth was made by histological analysis after amputation (Fig. 2). Only mice with documented primary tumor establishment and histological confirmation were used for data analysis in the pulmonary metastasis study and the local recurrence study.

\section{Statistical Computations}

A priori statistical power analyses based on experiments performed in our laboratory to develop the local recurrence and pulmonary metastases models indicated that with nine in each local recurrence study treatment group, we would have been able to detect $20 \%$ difference in recurrent longest tumor diameter between MSC and no MSC treatment groups for the local recurrence study. For the pulmonary metastasis study, to detect a $20 \%$ difference in days to first detection of metastasis, 20 animals would be required in each treatment group. Results were expressed as means \pm SD per treatment group and were analyzed
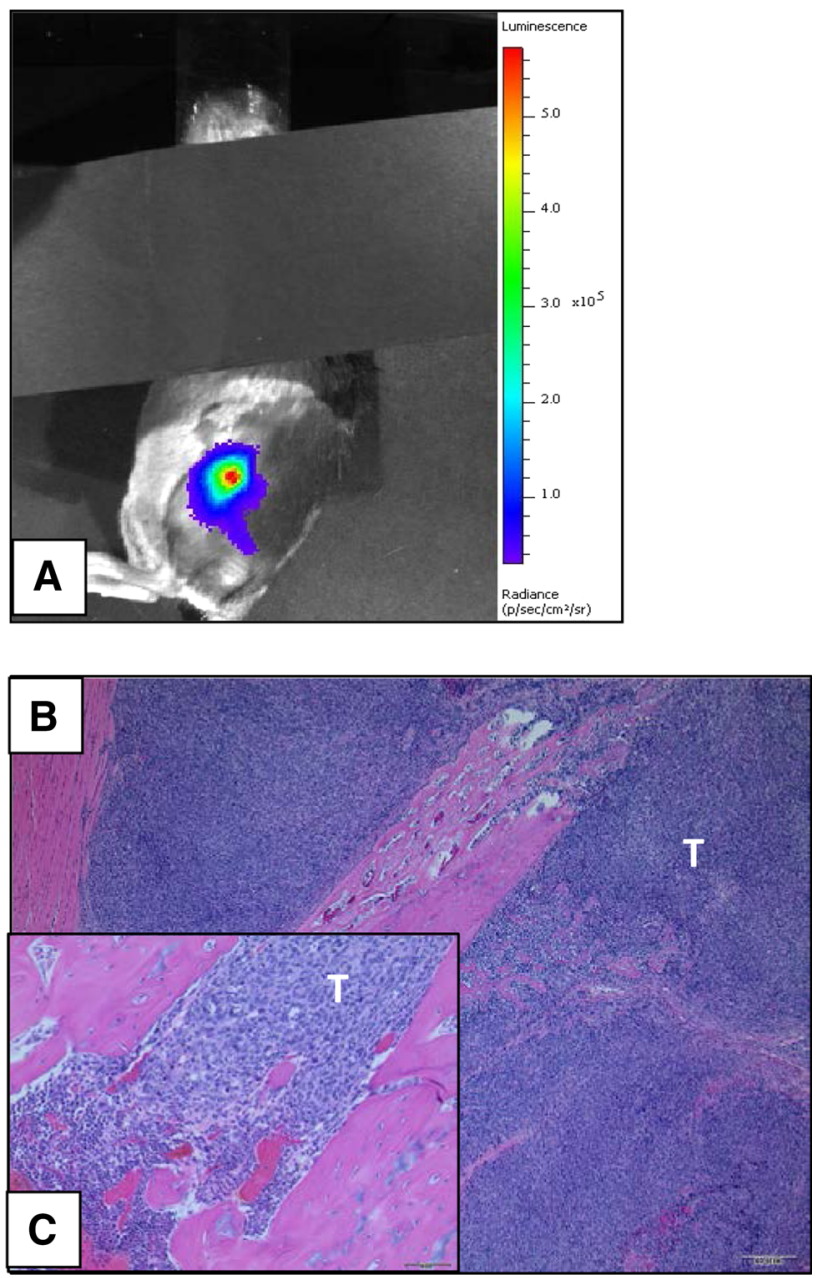

Fig. 2A-C (A) Bioluminescent image depicting luciferase expression in a primary tumor at Day 10 after inoculation. (B) Photomicrograph taken at $\times 10$ magnification showing histological confirmation of osteosarcoma in the proximal tibia (T) (C) Twenty times magnification of primary tumor. $\mathrm{T}=$ tumor within the tibia.

using analysis of variance (count of nodules and percent area), Welch's (time to bioluminescent imaging detection), or Kruskal-Wallis (tumor size and volume) with t-tests or Mann-Whitney tests (which data) for pairwise comparisons. For all tests, a p value of $<0.05$ was considered statistically significant.

\section{Results}

\section{Pulmonary Metastasis Study}

Mean number of days until first detectable metastasis as determined by bioluminescence imaging was shorter in the intravenous group $(2.93 \pm 1.90$ days $)$ than in the surgical site injection or no MSC groups (6.94 \pm 6.78 days and 5.93 
\pm 4.55 days, respectively, t-test with Welch's correction $\mathrm{p}=0.035$ and $\mathrm{p}=0.036)$ as well as between all groups $(\mathrm{p}=$ 0.022) using Welch's test (Fig. 3). The mean number of pulmonary metastatic nodules was $50 \pm 854$ in the intravenous MSC group, $24 \pm 62$ in the surgical site injection group, and $34 \pm 77$ in the no MSC group $(\mathrm{p}=0.441)$. With the numbers available, there were no differences in the median number of pulmonary nodules in the intravenous MSC group (median, 7.5; range, 0-325), surgical site MSC group (median, 1.5; range, $0-230$ ), and no MSC groups (median, 1.5; range, $0-267 ; \mathrm{p}=0.503$ ) (Fig. 4). The mean percentage of pulmonary metastatic area relative to total lung area was $4.62 \% \pm 7.20 \%$ in the intravenous MSC group, $2.26 \% \pm 4.98 \%$ in the surgical site injection group, and $3.95 \% \pm 9.33 \%$ in the untreated group. With the numbers available, there were no differences in the mean percentage areas between groups $(\mathrm{p}=0.55)$ (Table 1$)$.

\section{Local Recurrence Study}

With the numbers available, we found no difference in local recurrence between the MSC and no MSC treated groups in terms of local recurrence dimension or volume $(\mathrm{p}=0.221$ and $\mathrm{p}=0.524$, respectively). Histological

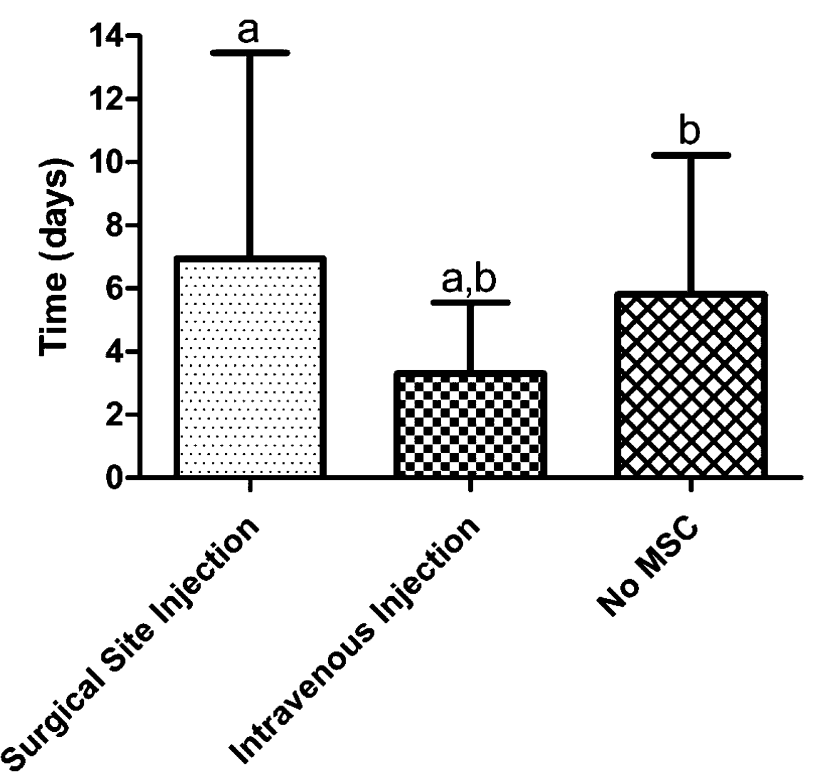

\section{Treatment Groups}

Fig. 3 Mean number of days until first detectable metastasis was determined by bioluminescence imaging. Mice treated with intravenous MSCs had significantly fewer days until first detection of metastasis by bioluminescence when compared with mice treated with a surgical site injection of MSCs ( $p=0.035$ denoted with " $a$ ") or when compared with mice treated with no MSCs $(p=0.036$; denoted with "b").
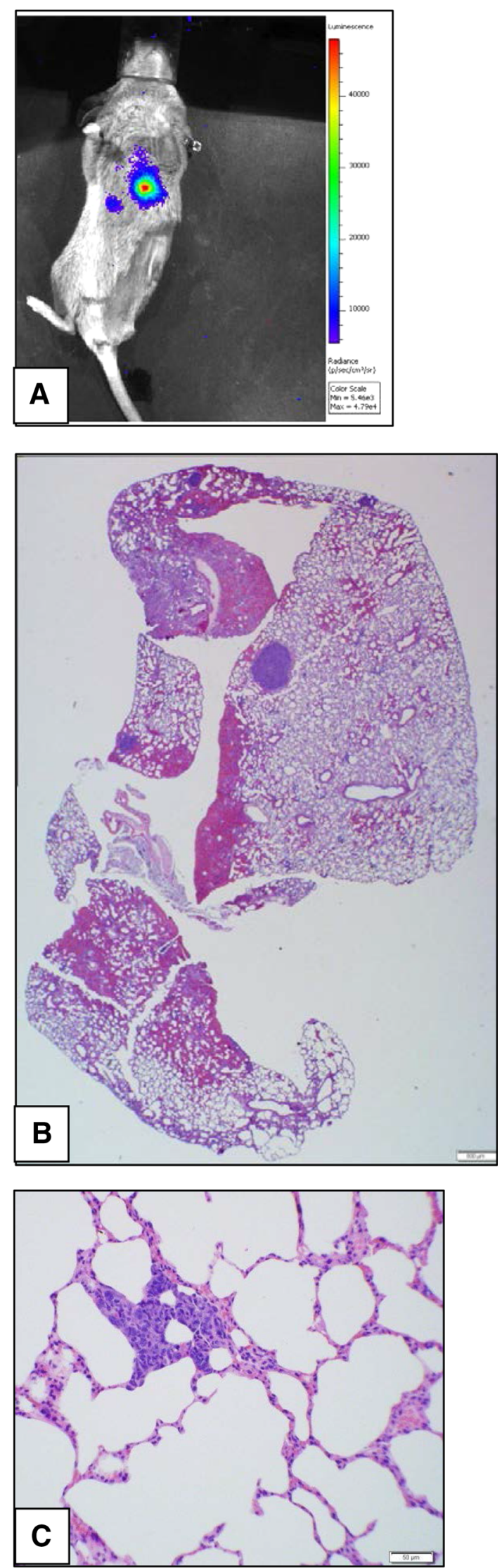
Fig. 4A-C (A) Bioluminescent image depicting luciferase expression of a metastatic nodule at Day 31 after inoculation. (B) Photomicrograph showing metastatic nodule at $\times 2$ magnification. (C) Metastatic pulmonary nodule shown at $\times 10$ magnification.

sections of the surgically resected limbs before MSC injection confirmed incomplete resection in all mice confirming the validity of the incomplete resection model. Histological examination of tissues from the surgical site at the time of euthanasia confirmed tumor recurrence in all mice (Fig. 5). Mean longest recurrent tumor diameter in the intravenous MSC group was $18 \pm 8 \mathrm{~mm}$ and mean recurrent tumor volume was $1397 \pm 1091 \mathrm{~mm}^{3}$. Mean longest recurent tumor diameter in the surgical site injection group was $14 \pm 5 \mathrm{~mm}$ and mean tumor voume was $1055 \pm 887 \mathrm{~mm}^{3}$. Mean longest diameter in the no MSC treatment group was $20 \pm 4 \mathrm{~mm}$ and mean tumor volume was $1584 \pm 329 \mathrm{~mm}^{3}$ (Table 2). A posteriori power analysis of the local recurrence study data revealed that the variability in the size of the recurrent tumors was greater than expected resulting in a statistical power less than $80 \%$ indicating that a Type II statistical error could be ruled out.

\section{Discussion}

It has been well established that pulmonary micrometastases exist early in the course of osteosarcoma and many patients have microscopic pulmonary disease at the time of diagnosis [18]. Furthermore, although the use of neoadjuvant chemotherapy and advanced imaging has improved our ability to safely perform limb salvage resection of the primary tumor, the safety of using MSCs at the surgical site when residual occult microscopic disease might be present has been questioned. The use of MSCs to augment bone healing in patients undergoing limb salvage after sarcoma resection may be promising [13], but the safety of MSC use in patients with sarcoma remains unknown [3].

We acknowledge several additional limitations to our study. This is a murine model so the findings are not directly applicable to the human setting. Animal models that recapitulate the natural disease progression as closely as possible are of paramount importance for translation of study results to human populations. This study used a novel murine osteosarcoma model that features spontaneous metastasis, pulmonary micrometastasis, and local recurrence after incomplete resection to study the influence of
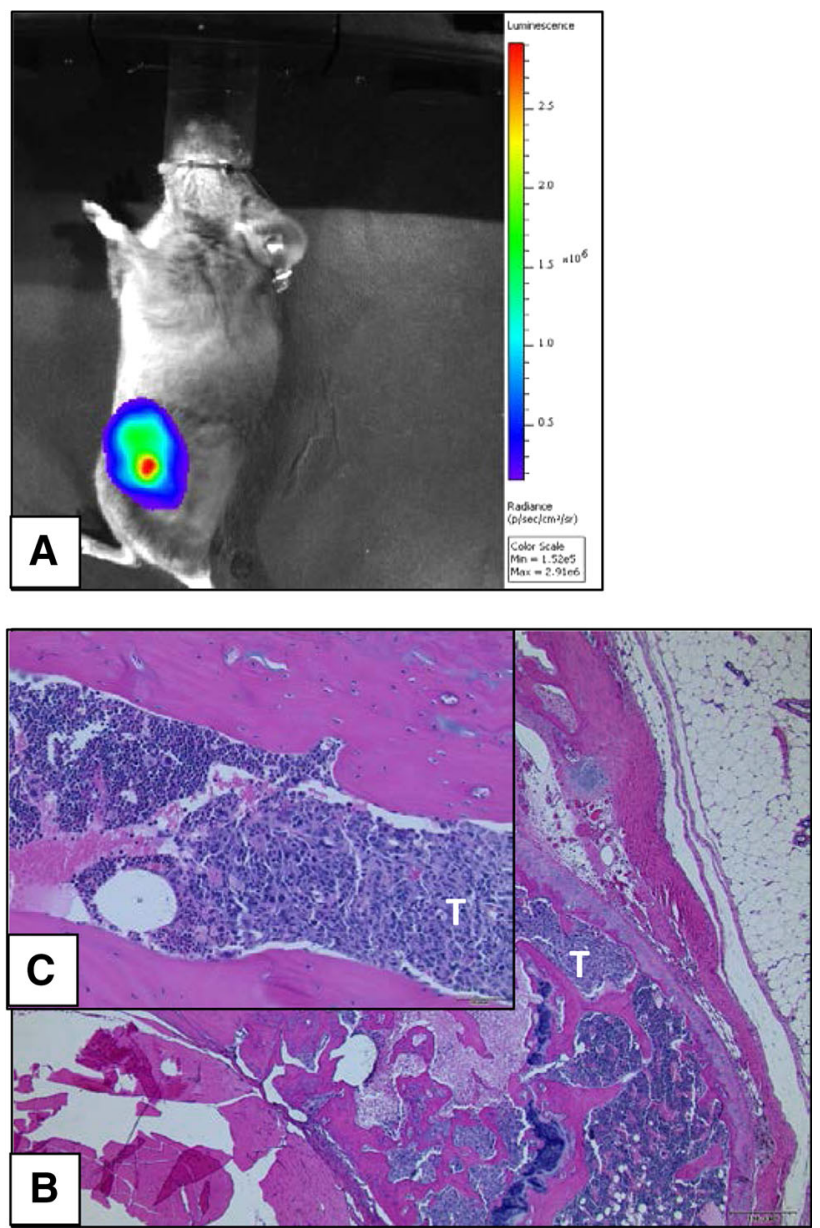

Fig. 5A-C (A) Bioluminescent image showing luciferase expression of a recurrent tumor at Day 39 after narrow margin amputation. (B) Photomicrograph of recurrent tumor within the distal femur (T) (C) Twenty times magnification. $\mathrm{T}=$ tumor.

Table 1. Quantitative values for measurement of pulmonary disease burden

\begin{tabular}{|c|c|c|c|c|c|c|c|c|}
\hline $\begin{array}{l}\text { Treatment } \\
\text { groups }\end{array}$ & $\begin{array}{l}\text { Mean } \\
\text { number of } \\
\text { days }\end{array}$ & $\begin{array}{l}\text { SD of } \\
\text { number of } \\
\text { days }\end{array}$ & $\begin{array}{l}\text { Mean number of } \\
\text { metastatic } \\
\text { nodules }\end{array}$ & $\begin{array}{l}\text { SD of } \\
\text { number of } \\
\text { nodules }\end{array}$ & $\begin{array}{l}\text { Median number of } \\
\text { metastatic nodules }\end{array}$ & $\begin{array}{l}\text { Range of number of } \\
\text { metastatic nodules }\end{array}$ & $\begin{array}{l}\text { Percent of } \\
\text { relative tumor } \\
\text { area }\end{array}$ & $\begin{array}{l}\text { SD of } \\
\text { percent } \\
\text { area }\end{array}$ \\
\hline No MSC & $5.8^{\dagger}$ & 4.41 & 34 & 77 & 1.5 & $0-267$ & 3.95 & 9.33 \\
\hline $\begin{array}{l}\text { Intravenous } \\
\text { MSC }\end{array}$ & 3.29 & 2.26 & 50 & 854 & 7.5 & $0-325$ & 4.62 & 7.2 \\
\hline $\begin{array}{l}\text { Surgical site } \\
\text { MSC }\end{array}$ & $6.94 *$ & 6.51 & 244 & 62 & 1.5 & $0-267$ & 2.26 & 4.98 \\
\hline
\end{tabular}

* Significantly different time between Intravenous MSC and surgical site MSC groups $(\mathrm{p}=0.035)$; ${ }^{\dagger}$ significantly different time between intravenous MSC and no MSC groups ( $\mathrm{p}=0.036)$; MSC = mesenchymal stromal cell. 
Table 2. Measurements of recurrent tumor after narrow margin amputation of primary osteosarcoma

\begin{tabular}{llllr}
\hline $\begin{array}{l}\text { Treatment } \\
\text { groups }\end{array}$ & $\begin{array}{l}\text { Mean } \\
\text { diameter }\end{array}$ & $\begin{array}{l}\text { SD of } \\
\text { diameter }\end{array}$ & $\begin{array}{l}\text { Mean } \\
\text { volume }\end{array}$ & $\begin{array}{r}\text { SD of } \\
\text { volume }\end{array}$ \\
\hline No MSC & 20 & 4 & 1584 & 329 \\
Intravenous MSC & 18 & 8 & 1397 & 1091 \\
Surgical site MSC & 14 & 5 & 1055 & 887 \\
\hline
\end{tabular}

MSC = mesenchymal stromal cell.

MSC administration on microscopic residual disease after primary tumor removal. This model is intended to be clinically relevant but may not truly mimic the residual disease burden after a limb salvage procedure in a clinical setting. We also acknowledge we may have had insufficient numbers of mice in each group to detect a significant difference and we did not do repeated experiments using this model to confirm our findings. Additionally, we only used one type of MSC so our findings cannot be applied to other methods of obtaining MSCs nor can we say that similar findings would occur with a different murine osteosarcoma model or cell line.

In these studies, intravenous injection of AD-MSCs decreased the time to first detection of metastatic disease as compared with the no MSC group or mice treated with MSC injection in the surgical site. With the numbers we had, we could not detect a difference in the mean number of pulmonary metastases and mean area of pulmonary metastatic tissue among the three groups. Although MSCs may have had minimal or no effect on endpoint pulmonary nodule number or metastatic area, there was an effect on time to onset of metastatic disease. Additionally, the amount of variability in both number of pulmonary nodules and overall pulmonary metastatic lung area within each treatment group may have precluded the ability to see a treatment effect. A posteriori power analysis indicated that despite an appropriately designed study based on a priori power analysis with regard to time to metastasis, the variability in number of pulmonary nodules seen in this particular model decreased statistical power for these particular outcome measures.

The second purpose of this study was to determine the influence of AD-MSCs on local tumor recurrence after narrow margin, histologically incomplete resection. With the number of mice we studied, we observed no influence on local tumor recurrence with injection of MSCs into the surgical site or intravenously in this model. At the time this study was conducted, there were no prior studies using a local recurrence model for osteosarcoma. The authors developed this model for the express purpose of testing the influence of MSCs on local recurrence in a surgical site with residual microscopic disease and used pilot experiments to develop power analyses to design the study. Nonetheless, a priori power analyses did not take into account the variation seen within treatment groups with respect to some of the measured outcome variables in the experimental data. Therefore, it is possible that the finding of "no effect" of MSCs in the local recurrence study may have been the result of a Type II statistical error. Further confirmatory studies with appropriately powered study designs will be required to confirm these results.

Previous investigators have shown that MSCs promote both primary and metastatic tumor growth when coinjected in the presence of established primary osteosarcoma or concurrently with osteosarcoma cell lines [3, 24, 28, 29]. This effect of MSCs has been shown with other tumor types as well $[4,14,20]$. It has been recently theorized that the homing and subsequent tumor-promoting effects of MSCs in the presence of primary osteosarcoma may be the result of nonspecific chemokine receptor interactions and the influence of growth factors such as vascular endothelial growth factor [29]. Nonetheless, the influence of MSCs on primary tumor growth and metastatic disease may differ depending on the degree of tumor burden (microscopic or gross). Furthermore, MSC behavior in the postsurgical environment-an environment rich with inflammation and growth factors-may differ in the setting of microscopic metastasis or microscopic residual disease at the surgical site. Our findings that the intravenous administration of MSCs in the presence of pulmonary micrometastasis caused more rapid onset of detectable metastasis is concerning, however, and requires confirmatory investigation. In addition, we have developed valuable models of osteosarcoma pulmonary micrometastasis and residual microscopic disease that may be of use for future studies.

\section{Clinical Relevance}

Intravenous administration of MSCs may promote micrometastatic pulmonary disease after removal of the primary tumor in osteosarcoma. Local administration into a surgical wound, even in the presence of residual microscopic disease, may be safe but further investigation is warranted before considering the use of MSCs in patients with a history of osteosarcoma.

Acknowledgments We thank Dr Douglas Thamm of the Flint Animal Cancer Center, Colorado State University, for his donation of the parental DLM8 cell line. We also thank the editor and the reviewers for their exceptionally helpful comments during the review process.

\section{References}

1. Asai T, Ueda T, Itoh K, Yoshioka K, Aoki Y, Mori S, Yoshikawa $\mathrm{H}$. Establishment and characterization of a murine osteosarcoma cell line (LM8) with high metastatic potential to the lung. Int $J$ Cancer. 1998;76:418-422. 
2. Berlin O, Samid D, Donthineni-Rao R, Akeson W, Amiel D, Woods VL Jr. Development of a novel spontaneous metastasis model of human osteosarcoma transplanted orthotopically into bone of athymic mice. Cancer Res. 1993;53:4890-4895.

3. Bian Z-Y, Fan Q-M, Li G, Xu W-T, Tang T-T. Human mesenchymal stem cells promote growth of osteosarcoma: Involvement of interleukin-6 in the interaction between human mesenchymal stem cells and Saos-2. Cancer Sci. 2010;101:2554-2560.

4. Biljana L, Marija M, Vladislav V, Bridgid M, Diana B, Stefan P, Nebojsa A, Miodrag LL, Miodrag S. Human mesenchymal stem cells creating an immunosuppressive environment and promote breast cancer in mice. Sci Rep. 2013;3:2298.

5. Coathup MJ, Kalia P, Konan S, Mirza K, Blunn GW. A comparison of allogeneic and autologous mesenchymal stromal cells and osteoprogenitor cells in augmenting bone formation around massive bone tumor prostheses. J Biomed Mater Res A. 2013;101A:2210-2218.

6. Comstock KE, Hall CL, Daignault S, Mandlebaum SA, Yu C, Keller ET. A bioluminescent orthotopic mouse model of human osteosarcoma that allows sensitive and rapid evaluation of new therapeutic agents in vivo. In Vivo. 2009;23:661-668.

7. Di Bella C, Aldini NN, Lucarelli E, Dozza B, Frisoni T, Martini L, Fini M, Donati D. Osteogenic protein-1 associated with mesenchymal stem cells promote bone allograft integration. Tissue Eng A. 2010;16:2967-2976.

8. Donati D, Di Bella C, Col angeli M, Bianchi G, Mercuri M. The use of massive bone allografts in bone tumour surgery of the limb. Curr Orthop. 2005;19:393-399.

9. Dunn TB, Andervont HB. Histology of some neoplasms and nonneo-plastic lesions found in wild mice maintained under laboratory conditions. J Natl Cancer Inst. 1963;31:873-901.

10. Dupont KM, Sharma K, Stevens HY, Boerckel JD, García AJ, Guldberg RE. Human stem cell delivery for treatment of large segmental bone defects. Proc Natl Acad Sci U S A. 2010;107: 3305-3310.

11. Fidler I. Selection of successive tumour lines for metastasis. Nat New Biol. 1973;242:148-149.

12. Granero-Moltó F, Weis JA, Miga MI, Landis B, Myers TJ, O'Rear L, Longobardi L, Jansen ED, Mortlock DP, Spagnoli A. Regenerative effects of transplanted mesenchymal stem cells in fracture healing. Stem Cells (Dayton, Ohio). 2009;27:1887-1898.

13. Kalia P, Bhalla A, Coathup MJ, Miller J, Goodship AE, Blunn GW. Augmentation of massive implant fixation using mesenchymal stem cells. J Bone Joint Surg Br. 2006;88:392.

14. Karnoub AE, Dash AB, Vo AP, Sullivan A, Brooks MW, Bell GW, Richardson AL, Polyak K, Tubo R, Weinberg RA. Mesenchymal stem cells within tumour stroma promote breast cancer metastasis. Nature. 2007;449:557-563.

15. Keibl C, Fügl A, Zanoni G, Tangl S, Wolbank S, Redl H, van Griensven M. Human adipose derived stem cells reduce callus volume upon BMP-2 administration in bone regeneration. Injury. 2011;42:814-820.
16. Khanna C, Prehn J, Yeung C, Caylor J, Tsokos M, Helman L. An orthotopic model of murine osteosarcoma with clonally related variants differing in pulmonary metastatic potential. Clin Exp Metastasis. 2000;18:261-271.

17. Liu X, Li X, Fan Y, Zhang G, Li D, Dong W, Sha Z, Yu X, Feng Q, Cui F, Watari F. Repairing goat tibia segmental bone defect using scaffold cultured with mesenchymal stem cells. J Biomed Mater Res B Appl Biomater. 2010;94B:44-52.

18. Luu HH, Kang Q, Park JK, Si W, Luo Q, Jiang W, Yin H, Montag AG, Simon MA, Peabody TD, Haydon RC, RinkerSchaeffer CW, He TC. An orthotopic model of human osteosarcoma growth and spontaneous pulmonary metastasis. Clin Exp Metastasis. 2005;22:319-329.

19. Miretti S, Roato I, Taulli R, Ponzetto C, Cilli M, Olivero M, Di Renzo MF, Godio L, Albini A, Buracco P, Ferracini R. A mouse model of pulmonary metastasis from spontaneous osteosarcoma monitored in vivo by Luciferase imaging. PLoS One. 2008; 3:e1828.

20. Muehlberg FL, Song YH, Krohn A, Pinilla SP, Droll LH, Leng X, Seidensticker M, Ricke J, Altman AM, Devarajan E, Liu W, Arlinghaus RB, Alt EU. Tissue-resident stem cells promote breast cancer growth and metastasis. Carcinogenesis. 2009;30:589-597.

21. Mueller F, Fuchs B, Kaser-Hotz B. Comparative biology of human and canine osteosarcoma. Anticancer Res. 2007;27:155-164.

22. Muscolo DL, Ayerza M, Aponte-Tinao L, Farfalli G. Allograft reconstruction after sarcoma resection in children younger than 10 years old. Clin Orthop Relat Res. 2008;466:1856-1862.

23. Ogilvie CM, Crawford EA, Hosalkar HS, King JJ, Lackman RD. Long-term results for limb salvage with osteoarticular allograft reconstruction. Clin Orthop Relat Res. 2009;467:2685-2690.

24. Perrot P, Rousseau J, Bouffaut A-L, Rédini F, Cassagnau E, Deschaseaux F, Heymann M-F, Heymann D, Duteille F, Trichet V, Gouin F. Safety concern between autologous fat graft, mesenchymal stem cell and osteosarcoma recurrence. PLoS One. 2010;5:e10999-e10999.

25. Picci P. Osteosarcoma (osteogenic sarcoma). Orphanet J Rare Dis. 2007;2:6.

26. Ramseier LE, Malinin TI, Temple HT, Mnaymneh WA, Exner GU. Allograft reconstruction for bone sarcoma of the tibia in the growing child. J Bone Joint Surg Br. 2006;88:95-99.

27. Sottnik J, Duval D, J. Ehrhart E, Thamm D. An orthotopic, postsurgical model of luciferase transfected murine osteosarcoma with spontaneous metastasis. Clin Exp Metastasis. 2010;27: 151-160.

28. Tsukamoto S, Honoki K, Fujii H, Tohma Y, Kido A, Mori T, Tsujiuchi T, Tanaka Y. Mesenchymal stem cells promote tumor engraftment and metastatic colonization in rat osteosarcoma model. Int J Oncol. 2012;40:163.

29. Zhang P, Dong L, Yan K, Long H, Yang TT, Dong MQ, Zhou Y, Fan QY, Ma BA. CXCR4-mediated osteosarcoma growth and pulmonary metastasis is promoted by mesenchymal stem cells through VEGF. Oncol Rep. 2013;30:1753-1761. 